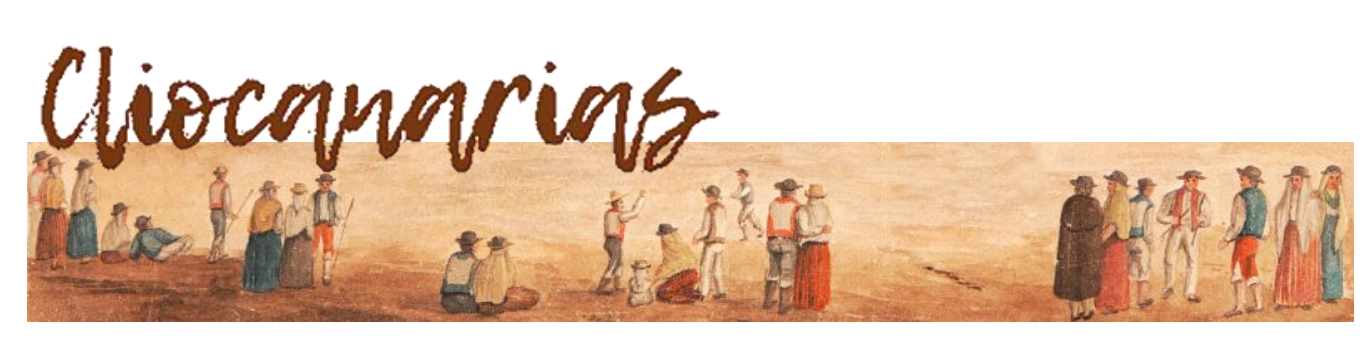

ISSN 2695-4494

https: / / doi.org/ 10.53335/cliocanarias.2021.3.26

\title{
LOS EXPEDIENTES JUDICIALES COMO FUENTE PARA LA RECONS- TRUCCIÓN DE ARCHIVOS FAMILIARES. EL EJEMPLO DEL ARCHIVO DEL ANTIGUO MARQUESADO DE LANZAROTE ${ }^{1}$
}

\begin{abstract}
JUDICIAL RECORDS AS A SOURCE FOR THE RECONSTRUCTION OF FAMILY ARCHIVES. THE EXAMPLE OF THE ARCHIVE OF THE FORMER MARQUESADO DE LANZAROTE
\end{abstract}

\section{Víctor M. BELLO JIMÉNEZ*}

RESUMEN: Los archivos familiares son una fuente de información de primer orden para el conocimiento del pasado. Sin embargo, muchas veces el traspaso de un título nobiliario de un linaje a otro, o la desatención por parte de sus propios titulares, ha provocado su desaparición. Tal es el caso del archivo del antiguo marquesado de Lanzarote, hoy en paradero desconocido y escasamente mencionado por la historiografia. Si bien la localización de un inventario de este, realizado en 1634, nos permite conocer qué había en ese momento en el archivo y nos habilita para reconstruirlo, en la medida de lo posible, junto al recurso de otras fuentes documentales como los expedientes judiciales, en los que figuran numerosas copias, trasladadas de sus originales, que fueron presentados como pruebas en pesquisas y juicios. En este estudio lo que se muestra es el valor de los archivos y expedientes judiciales para la reconstrucción de los archivos familiares desaparecidos.

PALABRAS CLAVE: Lanzarote, documento, archivo familiar, marquesado de Lanzarote, expedientes judiciales.

ABSTRACT: Family archives are a source of information of the first order for the knowledge of the past. However, many times the transfer of a noble title from one lineage to another, or the neglect on the part of its own holders, has caused its disappearance. Such is the case of the Archive of the former Marquesado de Lanzarote, now unaccounted for and scarcely mentioned by historiography. Although, locating an inventory of it, made in 1634 , allows us to know what was in the archive at that time and enables us to reconstruct it, as far as possible, together with the use of other documentary sources such

\footnotetext{
* Doctor en Historia y archivero independiente. C. e.: archiverobello@gmail.com

${ }^{1} \mathrm{El}$ presente artículo se enmarca en los resultados del proyecto "Reconstrucción histórica y documental del Archivo del antiguo marquesado de Lanzarote", adjudicado al autor por la Dirección General de Patrimonio Cultural del Gobierno de Canarias mediante resolución $62 / 2020$.
} 
as court records, in which there are numerous copies, transferred from their originals, which were presented as evidence in investigations and trials. In this study, what is shown is the value of the files and judicial files for the reconstruction of the missing family files.

KEYWORDS: Lanzarote, document, family archive, marquesado de Lanzarote, Court records.

\section{Introducción}

El estudio de los archivos familiares de Canarias ha ido cobrando fuerza en los últimos años, por lo que su localización, organización y estudio está dando lugar a la puesta en valor de una fuente documental fundamental para conocer el pasado isleño, como complemento de las fuentes provenientes de instituciones públicas ${ }^{2}$.

En este contexto se sitúa el interés por recuperar el archivo del antiguo marquesado de Lanzarote, si bien su intento de localización se remonta al año $1985^{3}$, aunque tuvo su momento álgido con la localización de un inventario de aquel en el Archivo Histórico de la Nobleza en el año $2017^{4}$.

Resulta evidente que el hallazgo de dicho instrumento de descripción no supone la localización del archivo tal cual se fue conformando, pero permite extraer diversas conclusiones: cómo estaba estructurado, qué documentos lo componian en la fecha de su realización, qué documentos habian desaparecido ya ${ }^{5}$ y las referencias necesarias, según la tipología documental de cada uno de ellos, para establecer un sistema de localización a partir de originales (como es el caso de los protocolos notariales, reales provisiones o reales cédulas) o de traslados incluidos en pleitos judiciales; asunto este último que será tratado en el presente trabajo.

\footnotetext{
2 En los últimos años ha crecido el volumen de estudios sobre estos archivos, sobre todo a partir de los proyectos de investigación desarrollados desde la Universidad de La Laguna. Algunos ejmplos son: GUTIÉRREZ DE ARMAS, Judith: El fondo "Conde de Siete Fuentes": la construcción de la memoria de linaje y la identidad aristocrática a través de un archivo de familia (siglos XVI-XX), Tesis doctoral, Universidad de La Laguna, 2019. Agradezco a Judith Gutiérrez el haberme dado acceso a la misma; Grupo ArchiCan: "Archivos familiares y personales de Canarias (siglos XVI-XX)", Cartas diferentes, n. ${ }^{\circ}$ 13, 2017, pp. 153-178; NÚÑEZ PESTANO, Juan Ramón, y Roberto ZALACAÍN GONZÁLEZ: "Promoción social y reconstrucción de la identidad familiar: el archivo de los Lercaro de Tenerife", en BELLO JIMÉNEZ, Víctor M. (Coord.): El Archivo. Poder, familia y derechos humanos, Mercurio editorial, Las Palmas de Gran Canaria, 2017, pp. 97-160.

3 BELLO JIMÉNEZ, Víctor M.: "En busca del arca perdida: el Archivo del antiguo Marquesado de Lanzarote (1402-1634)", IV Jornadas de Archivos de Teguise, 2021, inédito.

${ }_{4}^{4}$ Archivo Histórico de la Nobleza, Osuna, C, 2495, D 3.

5 Esta información es fácil colegirla a partir de las menciones a divesos documentos en expedientes judiciales anteriores a 1634 u otras fuentes.
} 
Los expedientes judiciales como fuente para la reconstrucción de archivos...

Se trata, por tanto de una información esencial para poder realizar una reconstrucción del archivo, en tanto se localiza el archivo original, si es que siguiera existiendo en la actualidad ${ }^{6}$.

\section{E1 Archivo del antiguo marquesado de Lanzarote: delimitación con- ceptual y cronológica}

La mera mención al archivo del antiguo marquesado de Lanzarote puede resultar una cuestión bastante etérea, dado que en la actualidad se desconoce por completo su último destino: si fue pasando de un linaje a otro de los que se sucedieron en el marquesado o si, simplemente, los documentos que lo componian se fueron desperdigando y, con ello, se desmembró un archivo que, a buen seguro, contenía los documentos escritos más antiguos de Canarias ${ }^{7}$.

Tampoco se tiene referencia alguna acerca de su posible existencia ahora, aunque sea en paradero desconocido, de ahí que previamente debamos definir qué entendemos por archivo del marquesado de Lanzarote y cuál es su delimitación cronológica al objeto de este estudio.

El marquesado de Lanzarote fue creado por Felipe II en el año 1584, cuando otorgó a Agustín de Herrera y Rojas ${ }^{8}$ el título de marqués de Lanzarote $^{9}$ por sus servicios en la defensa de territorios de la monarquía hispánica, lo que vino a sumarse al título de conde concedido en 156710 . Unos títulos con los que la familia descendiente de Inés Peraza alcanzó el grado de nobleza por segunda vez, dado que ya en tiempos de los Reyes Católicos había sido otorgado supuestamente el título de condes de La Gomera ${ }^{11}$.

Supuso esto el ascenso de un nuevo peldaño en la singladura del linaje Herrera-Peraza, que desde su arribo a las islas Canarias a mediados del siglo XV debía pretender la consecución del ennoblecimiento, de igual modo que dicho objetivo acompañaba a tantas familias que se aprestaron a la conquista de

${ }^{6} \mathrm{El}$ archivo estaba formado por 25 legajos, en los que primaban los documentos notariales (45\%), a los que siguen en volumen los relativos a la administración del estado (40\%), conformando el resto un grupo heterogéneo formado por documentos eclesiásticos, nobiliarios y judiciales. En el inventario figuran 651 entradas que abarcan un número mayor de documentos, dado que algunas de ellas se hacen bajo la denominación de legajo, legajillo, etc. El resultado final ha sido la localización de 453 unidades documentales (BELLO JIMÉNEZ, Víctor M.: "En busca del arca perdida...", art. cit.).

${ }^{7}$ En él se custodiaban documentos desde la posesión de las islas por parte de Jean de Bethencourt.

${ }^{8}$ LOBO CABRERA, Manuel, y Fernando BRUQUETAS DE CASTRO: Don Agustín de Herrera y Rojas, I Marqués de Lanzarote, Servicio de Publicaciones del Cabildo de Fuerteventura y Servicio de Publicaciones del Cabildo de Lanzarote, Madrid, 1995; RUMEU DE ARMAS, Antonio: "El Conde de Lanzarote, capitán general de la Madera", Anuario de Estudios Atlánticos, n. ${ }^{\circ}$ 30, 1984, págs. 415-416.

9 Archivo Histórico de la Nobleza, Osuna, C, 2495, D 27-28.

10 Archivo Histórico de la Nobleza, Osuna, C, 2495, D 1.

11 DÍAZ PADILLA, Gloria, y José Miguel RODRÍGUEZ YANES: El señorio de las Canarias Occidentales. La Gomera y El Hierro hasta 1700, Excmo. Cabildo de La Gomera, Excmo. Cabildo de El Hierro, 1991; BELLO JIMÉNEZ, Víctor M., y Enrique PÉREZ HERRERO: Inés Peraza, señora de Canarias. Corpus documental para la Historia de Canarias (1402-1503), en prensa (entre otros). 
nuevos territorios ${ }^{12}$. Podría considerarse, entonces, que el archivo del marquesado iniciaría su andadura en el momento de la obtención del título mencionado más arriba; pero es más acertado considerar que toda la documentación anterior, concerniente a la conquista, dominación, tenencia y explotación de las islas Canarias, relacionada con el linaje Peraza-Herrera, también forma parte de este archivo, toda vez que no se entiende la conformación del marquesado sin la existencia del señorío anterior, siendo aquel una consecuencia de este. Además, los documentos de los señores fueron un recurso permanente para la defensa de los intereses y derechos obtenidos por los marqueses en los siglos sucesivos, tal y como se evidencia en los pleitos mantenidos por diversas causas, puesto que el archivo del marquesado de Lanzarote constituyó un instrumento de legitimación del dominio que poseían, donde enraíza el interés por su mantenimiento y control. Se debe considerar este archivo, por tanto, como un objeto producido por un sujeto histórico multigeneracional, como es la familia $^{13}$, dado que en él debian conservarse los documentos de seis generaciones, si bien es necesario concretar que lo que se trata aquí se refiere, únicamente, a los documentos relativos a Canarias, en un principio, y a Lanzarote y Fuerteventura, posteriormente, y no a los producidos por todo el linaje familiar, concernientes a todo su patrimonio en diversos territorios.

Se apoya esta idea en la principal fuente que poseemos para la reconstrucción del archivo: el mencionado inventario de 1634, realizado con motivo del pleito seguido por los diversos pretendientes al mayorazgo de Lanzarote y Fuerteventura. En él solo figuran documentos alusivos a las propiedades y transacciones realizadas en Canarias, aparte de alguno referido a Madeira, por las relaciones existentes entre esta isla y el marquesado ${ }^{14}$; pero no se encuentra en él nada referente a posesiones peninsulares, lo que conduce a plantear la hipótesis de que toda la documentación familiar no estuvo nunca concentrada en un mismo lugar, sino custodiada en la casa familiar de cada uno de los territorios en los que tenían posesiones ${ }^{15}$. Esto nos ayuda a delimitar el alcance del archivo del marquesado de Lanzarote.

En lo que respecta al ámbito cronológico, el archivo aquí aludido es el correspondiente a la primera linea sucesoria en el marquesado, con antecesores y descendientes de Agustín de Herrera y Rojas I. La decisión estriba en que a

\footnotetext{
12 BELLO JIMÉNEZ, Víctor M., y Enrique PÉREZ HERRERO: Inés Peraza, señora de Canarias..., op. cit..

${ }^{13}$ GUTIÉRREZ DE ARMAS, Judit: El fondo "Conde de Siete Fuentes"..., tesis cit.

${ }^{14}$ Como se ha citado ya, el I marqués, siendo aún conde, fue capitán general de Madeira (cartas que testimonian su actividad, en [<https://archivoteguise.es/archivo/5/coleccionesdigitales>]; además, su hija Juana de Herrera fue casada con Francisco de Acciayoli y Vasconcelos, madeirense.

15 Induce a pensar así la existencia de un libro sobre posesiones sevillanas en el Archivo del Arzobispado de Sevilla, leg. 92. Ha sido estudiado por LADERO QUESADA, Miguel Ángel: "Los señores de Canarias en su contexto sevillano", Anuario de Estudios Atlánticos, 23, 1977, pp. 125-164; y por RUBIO MERINO, Pedro: «Permuta de la heredad de Valdeflores, en Aznalcázar (Sevilla) por la doceava parte de las Islas de Lanzarote y Fuerteventura, entre don Sancho de Herrera, el viejo, y don Sancho de Herrera, el mozo, su sobrino, vecinos de Sevilla", Coloquios de Historia Canario- Americana, IV, 1982, pp. 250-260.
} 
partir de la IV marquesa, doña Luisa Bravo de Guzmán, que falleció sin descendencia ${ }^{16}$, el marquesado pasó a un sobrino segundo de esta, perteneciente a la familia Atienza ${ }^{17}$, con lo que se produce la llegada a Lanzarote de un segundo linaje sin relación sanguínea con la precursora de aquel, Inés Peraza de las Casas.

Además, a partir de ese momento, la gestión y administración del estado de Lanzarote y Fuerteventura se lleva mediante arrendamientos a terceros por parte de los marqueses de Lanzarote, quienes tenían esta propiedad como algo menor dentro de sus bienes. De esta manera, lo que resulta relevante para este estudio es el archivo tal y como se estructuraba en tiempos de la IV marquesa, mientras la gestión del estado continuaba siendo directa por parte de los marqueses, aunque ya estuviesen más distanciados geográficamente de la isla, ya fuese por residir en Gran Canaria o en Madrid.

Por tanto, partimos de la base de que el archivo, que terminará siendo el del marquesado de Lanzarote, es eminentemente patrimonial, creado por los señores de Canarias atentos al constante cuestionamiento sobre los derechos de propiedad y cobro de sus rentas, lo que debió despertar una gran preocupación por la conservación de sus documentos.

En consecuencia, definimos el archivo del marquesado de Lanzarote como el conjunto de documentos producidos y recibidos por la familia Peraza-Herrera, relativos a Canarias, en primer término, y a Lanzarote y Fuerteventura, en segundo término, resultado de sus actividades patrimoniales, la defensa de sus intereses y la gestión y administración de las Islas en el periodo 1402 a 1634.

El motivo de la delimitación cronológica responde a las fechas extremas de los documentos que se custodiaron en el archivo desde la llegada del matrimonio Herrera-Peraza, como señores de las islas, hasta la realización del inventario del archivo en 1634. La inicial es fruto de las transacciones realizadas con anterioridad a ellos y la práctica habitual de entregar las escrituras junto con el territorio que se traspasaba ${ }^{18}$, lo que hizo que los Herrera-Peraza acumulasen documentos desde el periodo normando con la finalidad de demostrar la línea sucesoria en la propiedad de las islas Canarias.

\section{La administración de justicia en el marquesado de Lanzarote}

La pretensión de este epígrafe no es hacer un estudio novedoso, sino plasmar los órganos jurisdiccionales donde se pueden localizar documentos judiciales en los que el marquesado tiene una presencia extensa.

\footnotetext{
${ }^{16} \mathrm{Su}$ hijo, Agustín de Herrera y Rojas III, había fallecido siendo aún niño.

17 Una transcripción de este testamento puede encontrarse en BRUQUETAS DE CASTROS, Fernando: Memorial ajustado del estado de Lanzarote, 1771, Servicio de Publicaciones del Excmo. Cabildo Insular de Lanzarote, Irún, 2001.

18 De este asunto ya hablamos en BELLO JIMÉNEZ, Víctor, M. y Enrique PÉREZ HERRERO: Traspaso de las Islas Canarias al Conde de Niebla. 15 de noviembre de 1418. Estudio histórico y transcripción paleográfica de documentos. Mercurio editorial, Colección Universidad, 20, 2018.
} 
Tras el inicio de la conquista, los señores en los que fue recayendo la titularidad de Canarias poseyeron el mero y mixto imperio que los facultaba para arbitrar e impartir justicia, si bien la Corona siempre se reservó un gran recurso de alzada. En este contexto, los reyes se convirtieron en jueces y la monarquía en sinónimo de justicia, mientras la jurisdicción señorial era considerada como jurisdicción delegada, ante la cual la real fijaba límites ${ }^{19}$, por lo que los vasallos recurrieron a ella en diversas ocasiones ante lo que entendian abusos señoriales ${ }^{20}$. La pesquisa o el secuestro del estado del señorío, primero, y el marquesado, después, fue recurrente ante el continuo cuestionamiento al que era sometida tanto la autoridad señorial como su potestad para recaudar tributos a lo largo del siglo XV.

Imagen: Mapa de Lanzarote a fines del s. XVI, según L. Turriano (TOUS MELIÁ, Juan: Las islas Canarias a través de la cartografía, Gabino de Franchy editores, 2014, p. 49).

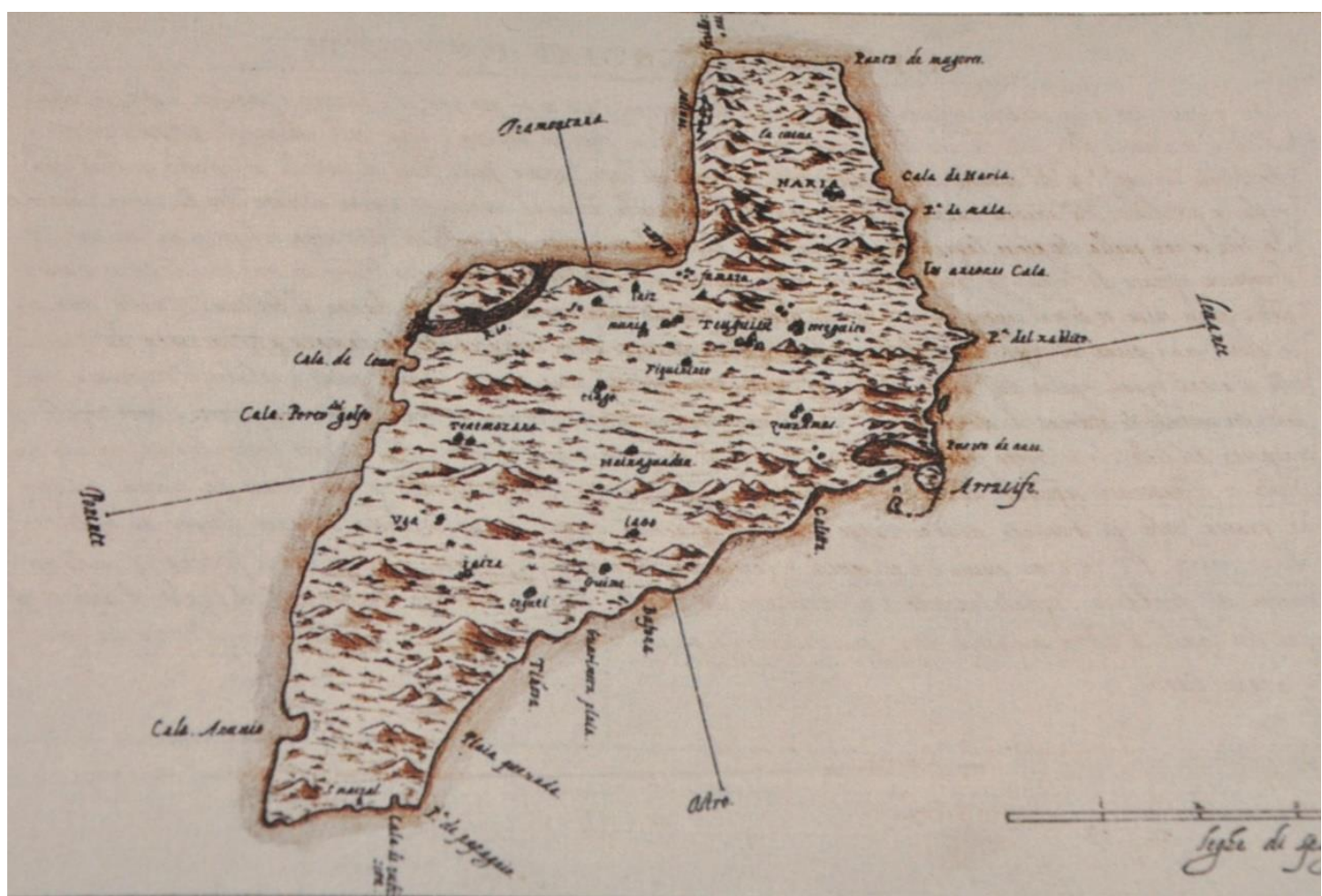

Con el siglo XVI aumentaron los tribunales superiores, constituidos por las Chancillerias, los Consejos y las Audiencias, que significaron una reafirmación del papel arbitral de la Corona ${ }^{21}$, que hizo uso de la Real Audiencia de

${ }^{19}$ LÓPEZ DÍAZ, Maria: "La administración de justicia señorial en el Antiguo Régimen", Anuario de Historia del Derecho Español, n. ${ }^{\circ} 76,2006$, pp. 557-588.

20 Un claro ejemplo de esto es la denominada Pesquisa de Cabitos (AZNAR VALLEJO, Eduardo: Pesquisa de Cabitos. Ediciones del Cabildo Insular de Gran Canaria, 1990).

${ }^{21}$ JIMÉNEZ BETANCOR, Miguel Ángel, y Rafael QUINTANA MONTESDEOCA, Rafael: «Historia de los Archivos Judiciales de Canarias", en PÉREZ HERRERO, Enrique: Historia de los Archivos de Canarias, Tomo II, Anroart ediciones, 2011, p. 189. 
Canarias, creada en 1526 y constituida un año después ${ }^{22}$, para controlar lo que sucedía en las islas de señorío.

El recurso a la justicia superior, como se ha dicho ya, fue común desde un inicio. El primero del que tenemos constancia es del auspiciado por Guillén de las Casas cuando reclamaba los derechos concedidos por Juan II a su padre, Alfonso de las Casas ${ }^{23}$, cuando las islas ya estaban en manos del II Conde de Niebla ${ }^{24}$. De este modo se plasmaba en el documento de traspaso efectuado en 1430:

\section{E por cuanto entre mi, el dicho Conde don Enrique, e mis procurado- res en mi nombre, de la una parte, e el dicho Alfonso de las Casas, vuestro padre, de la otra, avía pleitos e contiendas que están pen- dientes ante nuestro señor el rey e en el su Consejo, e ante los oydores de la su Abdiençia, e ante otros jueses de la su Corte e desta çibdad de Seuilla ${ }^{25}$.}

Pone de manifiesto este documento cuáles eran los órganos jurídicos que intervenían: la justicia local, la Audiencia y el Consejo, los mismos entes a los que es necesario acudir para recabar los documentos necesarios para la reconstrucción del archivo del que aquí se habla.

Tras ese primer traspaso, son muchos los juicios que tuvieron lugar. El más sonado y reconocido quizá sea la pesquisa encomendada por los Reyes Católicos a Esteban Pérez de Cabitos durante el gobierno de Inés Peraza y Diego García de Herrera ${ }^{26}$, cuyo resultado fue el fraccionamiento de las islas en territorios de señorío y realengo.

Inés Peraza, por unos motivos o por otros, tuvo una vida repleta de pleitos ${ }^{27}$, y también tras su fallecimiento continuaron a causa de la constitución de mayorazgo en su hijo Fernán Peraza, el joven, y el repartimiento posterior de las islas, ratificado a través de su testamento ${ }^{28}$.

La constitución del marquesado tampoco estuvo exenta de problemas. E1 fallecimiento de Agustín de Herrera y Rojas I supuso que su viuda, Mariana Manrique Enríquez de la Vega, debiera pleitear tanto contra sus acreedores como contra quienes pretendian ser los sucesores legítimos del mayorazgo

\footnotetext{
22 ROSA OLIVERA, Leopoldo: "La Real Audiencia de Canarias. Notas para su historia", Anuario de Estudios Atlánticos, vol. 1, n. ${ }^{\circ} 3$, 1957, pp. 91-161; JIMÉNEZ BETANCOR, Miguel Ángel, y Rafael QUINTANA MONTESDEOCA, Rafael: "Historia de los Archivos...", art. cit.

23 Archivo General de Simancas (AGS), CCA-DIV, 9,15.

${ }^{24}$ BELLO JIMÉNEZ, Víctor M. y PÉREZ HERRERO, Enrique: Traspaso de las Islas Canarias..., op. cit.

${ }^{25}$ AZNAR VALLEJO, Eduardo: Pesquisa..., op. cit., p. 82.

26 AZNAR VALLEJO, Eduardo: Pesquisa..., op. cit.; BELLO JIMÉNEZ, Víctor M., y Enrique PÉREZ HERRERO, Enrique: Inés Peraza, señora de Canarias..., op. cit.

${ }^{27}$ BELLO JIMÉNEZ, Víctor M. y PÉREZ HERRERO, Enrique: Inés Peraza, señora de Canarias..., op. cit.

28 Archivo Histórico Provincial de Las Palmas (AHPLP), Audiencia de Sevilla, expte. n. ${ }^{\circ}$ 15, fols. $299 \mathrm{v}-312 \mathrm{v} .^{\circ}$.
} 
constituido en Constanza de Herrera y Rojas ${ }^{29}$. El conjunto de disputas y pleitos ha favorecido la reconstrucción del archivo del antiguo marquesado de Lanzarote, toda vez que en ellos se han podido localizar copias de los originales ya desaparecidos, gracias a la obligación de presentar pruebas documentales que ratificaran los argumentos defendidos por unos y otros, las cuales se presentan a continuación ${ }^{30}$.

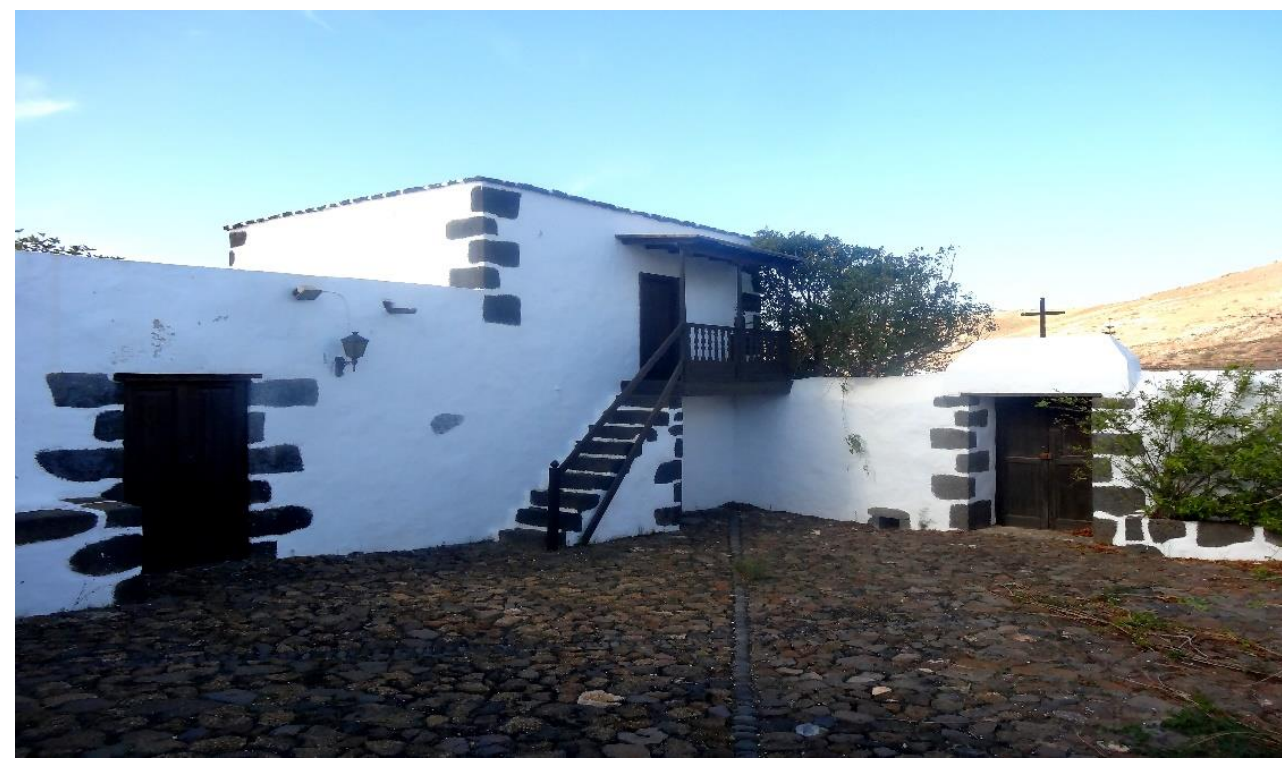

Imagen: Casa Peraza, en Los Valles (Teguise), posible ubicación del archivo en el siglo XV (foto del autor).

\section{Pleitos y documentos para la reconstrucción del archivo del antiguo marquesado de Lanzarote 31}

4. 1. Documentos del archivo en tiempos de Inés Peraza y Diego García de Herrera

29 Sobre algunos de estos pleitos puede verse: CLAR FERNÁNDEZ, José Manuel: "Pleitos por la sucesión al Marquesado de Lanzarote", XII Jornadas de Estudios sobre Lanzarote y Fuerteventura, Tomo I, Servicio de Publicaciones del Excmo. Cabildo Insular de Fuerteventura y Servicio de Publicaciones del Excmo. Cabildo Insular de Lanzarote, 2008, pp. 47-64; SEVILLA GONZÁLEZ, María del Carmen: "A propósito de los pleitos sucesorios sobre el señorío oriental de las Islas Canarias", X Jornadas de Estudios de Lanzarote y Fuerteventura, Servicio de Publicaciones del Excmo. Cabildo Insular de Fuerteventura y Servicio de Publicaciones del Excmo. Cabildo Insular de Lanzarote, 2004, pp. 31-42; SEVILLA GONZÁLEZ, María del Carmen: "Más aportaciones sobre los litigios relativos a los derechos dominicales en el señorio oriental", XI Jornadas de Estudios de Lanzarote y Fuerteventura, Servicio de Publicaciones del Excmo. Cabildo Insular de Fuerteventura y Servicio de Publicaciones del Excmo. Cabildo Insular de Lanzarote, 2006, pp. 87-98; VIERA Y CLAVIJO, José de: Noticias de la historia general de las islas Canarias, Ediciones Goya, edic. de 1982, Santa Cruz de Tenerife.

$30 \mathrm{El}$ proyecto de reconstrucción del archivo se desarrolló entre los meses de abril y diciembre de 2020, por lo que no puede considerar un proyecto cerrado, dado que es posible que en un futuro sigan apareciendo documentos relacionados con otros pleitos y copias de los originales habidos en el archivo.

${ }^{31}$ Los documentos referenciados se listan de forma correlativa para conocer el número total de los recuperados a través de la fuentes jurídicas. 
Con los inicios de ocupación normanda y con los sucesivos traspasos de las islas al conde de Niebla (1418), Guillén de las Casas (1435) y Hernán Peraza (1445), comienza a pergeñarse lo que posteriormente dará lugar en primera instancia al archivo del señorio de Canarias, que tendrá su punto fuerte de arranque con Inés Peraza de las Casas y Diego García de Herrera como señores de Canarias. Un archivo que se hace evidente en 1477, cuando durante el proceso abierto para esclarecer los derechos de posesión de dicho señorio presentan ante el pesquisidor Esteban Pérez de Cabitos documentos que primeramente habian pasado por manos de Jean y Maciot de Bethencourt, después por las del conde de Niebla (momento en que los documentos relativos al señorío de Canarias debieron estar repartidos entre Teguise, donde se es-tableció Maciot como gobernador, y Sevilla, donde vivía el conde propietario), y finalmente por las familias De las Casas y Herrera-Peraza, fruto de las transacciones realizadas con el territorio insular, hasta que llegó a manos de estos últimos, cuando el archivo ya se encontraba, probablemente, en Teguise, donde continuó en los años sucesivos.

Es lógico pensar que este fondo contenía numerosos documentos relativos a la administración del señorio y a las diversas transacciones realizadas por los Herrera-Peraza en su actividad comercial y conquista. La nómina de algunos de ellos es:

1. Real provisión de Enrique III de Castilla en la que autorizaba a Juan de Bethencourt a formar armada, al tiempo que ordenaba su protección, se le permitiese comprar grano y ganado y se le proveyese de guías, alimentos y posada, bajo pena de multa al que infringiese su orden. Año 1402.

2. Pleito-homenaje de Jean de Bethencourt a Juan II. Año 1412.

3. Privilegio de acuñar moneda conferido a Jean de Bethencourt.

4. Traslado o testimonio por exhibición del documento particular ( $\sin$ fe pública) otorgado en Granville (Francia) el 17 de octubre de 1418 por Juan de Vetancor, señor de Granvilla y de las islas Canarias, en atención a las estipulaciones del poder que en su día otorgó a su primo Maçote de Vetancor para que pudiera en su nombre vender, donar y alienar el señorío de dichas islas y al precio que estipulase libremente, por cuyo documento se reservaba para sí y sus herederos la isla de Fuerteventura y que quedase fuera de la esfera de dominio de Maçote. Año 1418.

5. Traspaso que Maciot de Bethencourt hace, en nombre de su tio Jean de Bethencourt, de la posesión y señorio de las islas Canarias a Enrique de Guzmán, II conde de Niebla. Año 1418.

6. Merced a Alfonso de las Casas de las islas no conquistadas y para formar armada en pro de su defensa. Año 1420.

7. Traspaso de los derechos del conde de Niebla sobre las islas Canarias a Guillén de las Casas. Año 1435.

8. Permuta de la heredad de Huévar por parte de las islas, entre Fernán Peraza e hijos y Guillén de las Casas. Año 1445. 
9. Real cédula para que las autoridades del reino presten ayuda a Fernán Peraza en la posesión de las islas.

10. Sobrecarta, a petición de Fernán Peraza, de la exención de quinto sobre las mercancias enviadas desde el archipiélago.

11. Real cédula para que los vecinos de Lanzarote guarden la sentencia del licenciado González de Taranco que concedió la posesión de dicha isla a doña Inés Peraza y Diego García de Herrera.

12. Sentencia del licencia Pedro González de Taranco en el pleito que enfrentó a Inés Peraza y Diego García de Herrera con Maciot de Bethencourt.

13. Traslado de la real cédula que anulaba la concesión de Tenerife, La Palma y Gran Canaria a los condes de Atouguia y Vilareal.

14. Real cédula autorizando a Diego García de Herrera y a doña Inés Peraza para instituir mayorazgo ${ }^{32}$.

15. Traslado del documento original escrito en pergamino otorgado ante Fernando de Párraga, escribano público, en el puerto de El Bufadero de la isla de Tenerife, el 21 de julio de 1464, mediante el cual los reyes de Tenerife reconocen a Diego de Herrera como señor de las islas Canarias y le rinden pleitesía. Una vez terminado el acto de posesión, Diego de Herrera les autoriza y encomienda que en su nombre gobiernen sus respectivos territorios como buenos y leales vasallos ${ }^{33}$.

16. Acta de toma de posesión de Gran Canaria. Año $1461^{34}$.

17. Escritura de donación de la isla de El Hierro a Pedro García de Herrera. Año147535.

18. Traslado del asiento de los RR. CC. por el que se dispone que Diego de Herrera e Inés Peraza, su mujer, y Fernando Peraza, su hijo, les cedan y traspasen todo derecho que tengan sobre las islas de Gran Canaria, Tenerife y La Palma, además de que nada puedan hacer sin la licencia de dichos monarcas o del capitán o capitanes que tuviesen en las islas, so pena de perder la merced y la confiscación de sus bienes. Asimismo solicitan la vigésima parte de lo que ganaren haciendo guerra en Tenerife, La Palma y África, y una vez terminadas las conquistas, solamente pagarán el quinto, entre otros extremos. S/ $\mathrm{f}^{36}$.

También arrancó en tiempos de Inés Peraza un pleito que nos muestra otros documentos que se albergaron en el archivo del marquesado de Lanzarote. En

32 Estos documentos estaban en el archivo de Lanzarote, tanto en 1477 como en 1527. Han sido listados a partir de las referencias de la pesquisa de Cabitos (AZNAR VALLEJO, Eduardo: Pesquisa..., op. cit.). Archivo Histórico Provincial de Sevilla (AHPS), Protocolos notariales, legajo 19.735P, fols. 108r- 129r, y Real Academia de la Historia (RAH), Colección Salazar y Castro, M-11.

${ }^{33}$ Archivo Histórico Provincial de Santa Cruz de Tenerife (AHPSCT), Prot. Not., legajo 1.106, fol. 54.

${ }^{34}$ ABREU Y GALINDO, Fray Juan: Historia de la conquista de las siete islas de Canaria, Goya ediciones, edic. de 1977, pág. 115.

35 AGS, Consejo Real de Castilla, leg. 2-3.

36 AHPS, Prot. Not., legajo 19.735P, fols. 108r- 129r.; RAH, Colección Salazar y Castro, M-11. Estos documentos se hallan en edición facsímil y transcritos en BELLO JIMÉNEZ, Víctor M., y Enrique PÉREZ HERRERO: Inés Peraza, señora de Canarias..., op. cit. 
esta ocasión se trató de un conflicto entre los titulares del señorío, el Cabildo Catedral de la Diócesis, el obispo y el monarca por la dehesa ganadera de Jandía. Una disputa ya planteada, al menos, desde $1484^{37}$ y cuya primera tentativa de solucionarlo se produjo en 1500; una concordia que, junto a otros documentos, fue protocolizada en 1774 ante el escribano de Las Palmas de Gran Canaria José Agustín Alvarado. En dicho protocolo consta:

19. Documento de concordia sobre el pleito que pendia entre el deán y Cabildo Catedral e Inés Peraza y Sancho de Herrera por la dehesa de Jandía. Año 1500 .

20. Poder otorgado por Inés Peraza a Sancho de Herrera para ratificar la concordia sobre el pleito por la dehesa de Jandía. Año 1500

32. Poder y ratificación del acuerdo por la dehesa de Jandía. Año 1500.

21. Poder especial que Agustín de Herrera y Rojas otorga al capitán Diego de Brito y Lugo, Juan Baptista Pérez de Medina, racionero de la catedral de Canaria, y al licenciado Alonso Fernández de Saavedra, regidor de dicha isla y abogado de la Real Audiencia, residentes en Gran Canaria, para que en su nombre puedan concretar con el Cabildo de la Iglesia los plazos y condiciones de la deuda del otorgante. Año 1620.

22. Copia certificada ante Juan de Quintana del convenio de pago que el capitán Diego de Brito y Lugo, alcalde mayor de Lanzarote, como apoderado de Agustín de Herrera y Rojas, hizo ante Juan Baptista Espino, canónigo doctoral de la Iglesia Catedral, por el tributo de 200 ducados anuales que adeuda el marqués a la Iglesia por las marcas vieja y nueva del ganado de Jandia. Año 1620.

23. Acta del acuerdo tomado en el que se informa de las condiciones y plazos que se dan para que se firme la escritura de espera para el cobro del tributo de la marca de Jandia, adeudado por el marqués de Lanzarote.

24. Reconocimiento del título y deuda del tributo del ganado de la marca de Jandia que Agustín de Herrera y Rojas hace ante Francisco Amado. Año $1620^{38}$.

También fueron protocolizados en 1815, ante Nicolás Oramas y Rojas ${ }^{39}$. Ahora figuran nuevos documentos, como son:

25. Ejecutoria de la sentencia de la apelación en revista que, ante la Real Audiencia de Sevilla, hicieron el deán y Cabildo Catedral de Canaria y Enrique Henriquez de la Vega, como tutora y curadora de Agustín de Herrera y Rojas, marqués de Lanzarote y Fuerteventura, sobre el pleito entablado por el impago de los tributos del ganado de las marcas vieja y nueva de Jandía. Año 1608.

26. Acta de notificación a la marquesa. Año 1608.

37 QUINTANA ANDRÉS, Pedro C. y Argelia CAMINO PÉREZ: Litigio sobre la dehesa de Jandía (1500-1815), Gobierno de Canarias, Las Palmas de Gran Canaria, 2016, p. 84.

38 Todos estos documentos se encuentran publicados en QUINTANA ANDRÉS, Pedro C. y CAMINO PÉREZ, Argelia: Litigio sobre la dehesa de Jandía, op. cit., pp. 91 y ss.

39 AHPLP, Prot. Not., leg. 2.082, fols. 412r-438r. 
27. Sentencia de apelación de la Real Audiencia de Sevilla, confirmando la de Canarias. Año $1612^{40}$.

Estos documentos - si no todos, sí muchos de ellos- estaban en el archivo del marquesado en 1634, cuando se inventaría.

Como se expone más arriba, tras la muerte de Inés Peraza volvió a surgir la polémica a raíz de su testamento en el que hacía el reparto de las islas bajo su dominio, y que dividía el señorío en dos: el occidental, formado por El Hierro y La Gomera, para los herederos de Fernán Peraza y Beatriz de Bobadilla; y el oriental, con Lanzarote y Fuerteventura fragmentadas en doceavas partes y repartidas entre sus hijos Sancho de Herrera, Maria de Ayala y Constanza Sarmiento.

Era el año 1504 cuando en el Consejo Real de Castilla se inició un pleito entre Guillén de las Casas, vecino de Sevilla, contra Guillén Peraza y Beatriz de Bobadilla sobre la propiedad de la isla de La Gomera. A dicho pleito se fueron sumando otros como Sancho de Herrera, en representación de sí mismo y de sus hermanas y Pedro García de Herrera, hijo de Inés Peraza y Diego García de Herrera, que había quedado desheredado ${ }^{41}$. En el proceso se van añadiendo pruebas por las dos partes, lo que da lugar a la acumulación de un buen número de traslados de documentos que ha sido imposible localizar por otras vías y que, a buen seguro, se encontraban en el archivo señorial. Es el caso de:

28. Donación de La Gomera a Fernán Peraza. Año 1478.

29. Testamento de Inés Peraza del año 1482.

30. Ratificación del primer testamento de Inés Peraza. Año $1482^{42}$.

En 1547, otro pleito -en esta ocasión suscitado por el conde de La Gomera- se vuelve a acudir al archivo del señorío con el propósito de obtener copia de una serie de documentos. La petición dice así:

En la ysla de Lançarote, en veynte e tres dias del mes de jullio del Nuestro Sennor Ihesu Christo de mill e quinientos y veynte e siete annos, ante mí, Gómez Gonçales de Grado, escriuano e notario público de sus magestades y en la su Corte y en todos los sus reynos e sennorios, e otrosi reçebtor nombrado por sus magestades e por los sennores contadores mayores, juezes de sus rentas e hazienda, estando presente el noble sennor Sancho de Herrera, hijo de Diego de Herrera e de donna Ynés Peraça, su muger, questén en gloria, sennor en las yslas de Lançarote e Fuerteventura, paresçió y presente Alonso de Valladolid, vezino de la ysla de La Gomera, en nombre e como procurador ques del magnífico sennor don Peraça d'Ayala, condes de La Gomera, según que tiene poder bastante para en este caso ante mi, escriuano, e presentó e leer fizo a mi, el dicho escriuano, vna carta e provisión de su magestad, firmada de los sus contadores mayores e refrendada e senalada

40 Todos estos documentos se encuentran publicados en QUINTANA ANDRÉS, Pedro C., y Argelia CAMINO PÉREZ: Litigio sobre la dehesa de Jandia..., op. cit., pp. 143 y ss.

41 Ibid.

42 Estos documentos se encuentran en traslado en AGS, Consejo Real de Castilla, leg. 2-3. 
e sellada con un sello real, e presentada e leyda por mí, el dicho escriuano y reçebtor. Dixo que pedia e requería el dicho Sancho de Herrera que, por quanto en nombre de su parte es ynformado que en su poder, como hijo y heredero del dicho Diego de Herrera e donna Ynés Peraça, su muger, estas çiertas escripturas originales e treslados abtorizados, signados de escriuanos públicos, que fincaron de los dichos Diego de Herrera y donna Ynés Peraça, su muger, que son çédulas de los Reyes Católicos, don Fernando e donna Ysabel, e contratos y mercedes $y$ donaçiones $y$ poderes $y$ otra escripturas que son y fablan sobre el derecho y abçión que los dichos Diego de Herrera e donna Ynés Peraça, su muger, tuvieron en sus dias a las yslas de Canaria e sennorio e dominio dellas, e agora a e tiene el dicho conde su parte e los otros herederos del dicho Diego de Herrera y donna Ynés Peraça, su muger, e agora el dicho conde su parte, es menester e neçesario vn treslado de las dichas cartas y sédulas e contratos y escripturas abtorizados para en prueva de su yntençión en el dicho pleyto ${ }^{43}$.

Los documentos trasladados entonces, de los cuales han sido señalados ya algunos más arriba, evidencian que Sancho de Herrera no sólo heredó documentos del reinado de los Reyes Católicos sino también anteriores, desde época de Enrique III. A la nómina de los ya detallados, podemos añadir otros dos más:

31. Carta de Isabel la Católica a Pedro de Vera, gobernador de las islas Canarias, en la que le informa que ha de pagar a la Corona la veintena de las presas que Diego de Herrera y sus hijos y hueste hicieran en las guerras en las islas de Tenerife, La Palma y en África, más las tercias de las islas de Lanzarote, Fuerteventura, La Gomera, El Hierro y otros extremos. Año 1484.

32. Carta de los RR. CC. a Inés Peraza y Diego García de Herrera, su marido difunto, por la que reconoce haber recibido todas las escrituras y títulos originales que tuviese sobre el dominio de las islas, que habia depositado en el monasterio de las Cuevas de Sevilla, por haberle librado ya los cinco cuentos de maravedís que le prometieron por la renuncia de las islas. Año 1495.

La evidencia de la existencia del archivo durante todo este tiempo es meridiana, pero nada sabemos acerca del modo en que pudiera estar organizado ni dónde se custodiaba. Según la costumbre de la época, lo normal es que estuviese custodiado en un arca. Tampoco sabemos si el archivo viajaba con los señores de un lugar a otro, dado que Inés Peraza de las Casas no hace alusión alguna a documentos en ninguno de los dos testamentos que otorgó. Sí que sabemos que los documentos estaban en Lanzarote, tanto por la data tópica del documento extractado anteriormente como por la orden dada por el emperador Carlos V para que se sacasen traslados, donde dice que:

Sepades que por parte del dicho Conde nos fue fecha relaçión diziendo que él tiene ciertas escripturas e previllejos originales en las yslas $/ 2$ de Lançarote y Fuerteventura ${ }^{44}$.

\footnotetext{
43 AHPS, Prot. Not., Legajo 19.735P, fol. 108r- 129r.; RAH, Colección Salazar y Castro, M-11. 44 Ibid.
} 
Como se observa en el anterior documento, el archivo no estaba en manos del conde de La Gomera, sino de su pariente Sancho de Herrera, quien juraba que no existían más escrituras que:

Primeramente vna escriptura signada de vn Martín Rodrigues, escriuano de Seuilla, de donaçión que fizo Maçiote de Bentancor [sic] en nombre de monsén Juan de Betancor, su tio, y se dezia de las yslas de Canaria al conde don Enrrique, que se dezia conde de Niebla; e un poder que para ello le dio el dicho monsén Juan de Betancor al dicho Maçiote, su sobrino, firmado del nombre del dicho mosén Juan, en pergamino; e vna carta del rey don Enrrique en que mandava que no fiziesen ningunas personas de sus reynos ningún mal ni danno al dicho mosén Juan de Betancor ni a los suyos, firmada del rey; e un açiento y contrato e capitulos, que por virtud dellos se fizo la renunçiaçión de las yslas de Canaria, e por Diego de Herrera y donna Ynés Peraça, su muger, en los Reyes Católicos, fecha por mandado de los Reyes Católicos, don Fernando e donna Ysabel, firmada del dotor Villalón, a quien fue mandado por los Reyes Católicos firmarla e ordenarla; e vna sédula firmada de los Reyes Católicos, don Fernando e donna Ysabel, por virtud de la dicha contrataçión, dada e sennalada del secretario Juan de Parra; otra çedula firmada de la reyna donna Ysabel e sennalada de Alonso Dávila, su secretario, en que mandava a Pedro de Vera, su capitán, cumplir lo contenido en el contrato e asiento, sédulas en este caso por ellos dada ${ }^{45}$.

Sancho de Herrera, celoso del archivo heredado y sabedor de su valía y necesidad para argumentar la defensa de su patrimonio insular y las razones por las que los Herrera-Peraza habian poseído y poseían las islas, negó cualquier posibilidad de que los documentos abandonasen la isla para que fuesen trasladados ante el teniente de Gran Canaria, como pretendía Alonso de Valladolid, pues

el dicho Sancho de Herrera dixo quel no hera obligado a lo sacar de su poder, por ser escripturas originales e no aver otras, porque an de pasar mar e se podrian perder e que por esta razón no las dará ${ }^{46}$.

Finalmente, los traslados se realizaron en Lanzarote, los cuales fueron 1levados a Sevilla, donde se insertaron en el protocolo de Mateo Almonacir, gracias a lo cual han llegado hasta nuestro días.

\subsection{Documentos y pleitos en el periodo del antiguo marquesado}

En torno al año 1588 el marqués de Lanzarote debía demostrar bajo qué derechos podía cobrar los quintos, y recurre para ello al licenciado Luis Melián de Betancor, abogado de la Audiencia de Canarias, quien tras profundizar entre los papeles conservados en el archivo del maquesado compuso una obra que títuló: Este es el origen de las yslas de Canaria, de su conquista, y una memoria de papeles reconocidos en Simancas, que a su vez subtituló como $E l$

45 Ibid.

46 Ibid. 
origen y principio de la conquista y posesión de las yslas de Fuerteventura y Lanzarote, $y$ el derecho que para llebar los quintos tiene el marqués de Lanzarote $^{47}$.

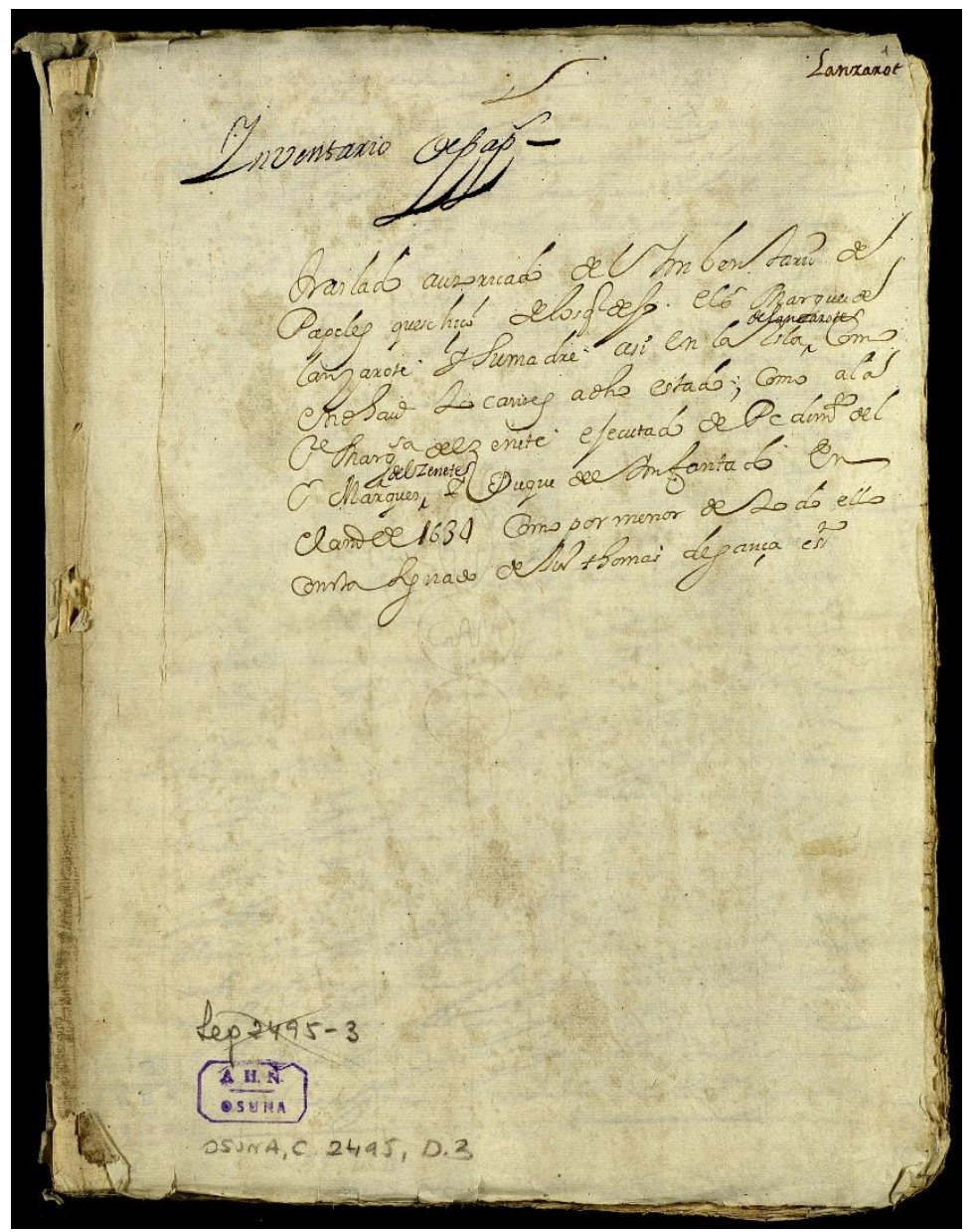

Imagen: Portada del inventario del archivo del marquesado de Lanzarote, 1634 (Archivo Histórico de la Nobleza, fondo Osuna, C 2.494, D 3) (Foto del autor).

En el detallado estudio de Rumeu de Armas se analiza tanto al autor como la obra y nos aporta una rica información acerca de los contenidos del archivo del marquesado en esos años. De inicio, Rumeu duda acerca de la posibilidad de que todos los documentos aludidos por Melián Betancor estuvieran en la isla en 1588, dados los frecuentes ataques sufridos por Lanzarote en el siglo XVI, que pudieron mermar el archivo señorial ${ }^{48}$. No lo podemos saber a ciencia cierta pero, aunque Rumeu lo ponga en duda, debemos dejar abierta la posibilidad de que muchos de ellos existieran aún, aunque -como insiste este autor- en el siglo XVIII no sobreviviese nada de esto, según aseguraba el conde de La Gomera y marqués de Adeje ${ }^{49}$; aún así, algunos de los referenciados por

\footnotetext{
47 Archivo Histórico Nacional (AHN), Consejos, leg. 34.202, expte. 1. ${ }^{\circ}$, fols. 109-118. Estudiado y publicado por RUMEU DE ARMAS, Antonio: "'El origen de las Islas de Canarias" del licenciado Luis Melián de Betancor", Anuario de Estudios Atlánticos, 24, 1978, pp. 15-79.

48 Ibid., p. 31.

49 Ibid.
} 
el letrado están presentes en los traslados hechos en 1547, por lo que bien podrian haber sobrevivido a los ataques $\operatorname{corsarios}^{50}$.

Pero el interés de esta obra, más allá de que los originales existieran en 1588 o no, estriba en la información que aporta sobre los documentos usados en la defensa de los interés del marqués. Muchos de ellos han sido reseñados ya, pues se encontraban insertos en la pesquisa de Cabitos, pero otros aparecen por primera vez, aunque se trate únicamente de una mención breve a ellos y con títulos poco o nada alusivos al tipo documental:

33. Toma de posesión de Gran Canaria realizada en La Isleta. Año $1461^{51}$.

34. Acta del Bufadero. Año 1464.

35. Documento en el que se testimonia que Maciot de Bethencourt es veinticuatro del Ayuntamiento de Sevilla.

36. Concordia entre Guillén de las Casas, señor de las Canarias, y Maciot de Bethencourt. Año 1432.

38. Confirmación hecha por el rey de Castilla Juan II, a los vecinos de Lanzarote y Fuerteventura del privilegio del quinto. Año 1433.

39. Queja del rey de Castilla Enrique IV ante el rey de Portugal Alfonso V del comportamiento de los portugueses en las islas Canarias. Año 1460.

40. Provisión del rey de Portugal Alfonso V para que el caballero Diogo da Silva entregase a Diego García de Herrera la fortaleza de Gando y la isla de Gran Canaria. Año 1461.

41. Pleito homenaje que hace Diogo da Silva a Diego García de Herrera como alcaide de la fortaleza de Gando. Lanzarote, 30 de septiembre de 1462.

42. Revocación hecha por Alfonso de la concesión de las islas Canarias hecha por su hermano Enrique IV en provecho de los condes de Aotuguia y Vila Real. Año 1466.

43. Asiento entre los Reyes Católicos y los señores de las Canarias por el que estos últimos renunciaban al señorío y conquista de las islas de Gran Canaria, Tenerife y La Palma. Año 1477.

44. Renuncia que hace Inés Peraza en favor de la Corona al dominio jurisdiccional sobre las islas de Gran Canaria, Tenerife y La Palma. Año 1477.

45. Escritura por medio de la cual Inés Peraza declara islas partibles las de Lanzarote y Fuerteventura. Año 1502.

\footnotetext{
50 Es el caso, por ejemplo del poder otorgado por Jean de Bethencourt a Maciot para enajenar las islas Canarias, un documento que Viera y Clavijo pudo leer en 1777 en Madrid, donde estaba en posesión de don Pedro Acedo Bethencourt.

${ }^{51}$ Sobre este documento dice Rumeu que es más explícito Abreu y Galindo. Esto viene a validar la conservación de dichos documentos en el archivo del marquesado en 1588, dado que si - como sostienen algunos investigadores- Abreu y Galindo es en realidad Argote de Molina, este pudo consultar los documentos incluso años después de que lo hiciera Melián de Betancor (SIEMENS HERNÁNDEZ, Lothar: "Argote de Molina y Abreu Galindo: dos líneas que tienden a converger", El Museo Canario, 1988-1991, pp. 59-70; CEBRIÁN LATASA, José Antonio: "Gonzalo Argote de Molina y su Historia de Canarias inacabada", Cartas diferentes. Revista canaria de patrimonio documental, n. ${ }^{\circ} 4,2008$, pp. 17-104).
} 
46. Confirmación hecha por el papa Alejandro VI a Inés Peraza de todos los derechos, privilegios y libertades que tenía sobre las islas Canarias. Año 1493.

47. Provisión mediante la que los Reyes Católicos ratifican las cesiones hechas en relación con el señorío de Canarias y confirman a Inés Peraza en los demás derechos y privilegios. Año1494.

Una vez más se destaca la idea patrimonial del archivo sin que sepamos, en esta ocasión, nada al respecto de dónde se encontraba ni cómo estaba organizado, aunque las noticias posteriores nos conducen a pensar que el lugar de custodia era el palacio de los marqueses y que los documentos debían estar albergados en baúles, como ya indicamos anteriormente.

El I marqués de Lanzarote dejó enormes deudas a su muerte, por lo que tras esta la marquesa Mariana Manrique debió afrontar la demanda interpuesta por sus acreedores, que se cruzó en el tiempo por el juicio suscitado por la sucesión del estado. Agustín de Herrera y Rojas I había fundado mayorazgo en su hija natural Constanza de Herrera ${ }^{52}$, pero tanto ella como los hijos habidos con Gonzalo Argote de Molina fallecieron con anterioridad, lo que supuso que la otra hija reconocida, Juana de Herrera y el esposo de esta, el madeirense Francisco de Acciayoli y Vasconcelos, reclamaran lo que consideraban sus derechos legítimos, enfrentándose asi a Mariana Manrique como tutora y curadora del II marqués, su hijo, mientras que, por otro lado, las hermanas de la primera esposa de Agustín de Herrera y Rojas I, Inés Benítez de las Cuevas, reclamaban lo que esta había previsto en su testamento que fuera para ellas.

La nómina de documentos que han podido localizarse en este pleito es la que sigue ${ }^{53}$ :

48. Promesa de dote que hace Pedro de Aponte, regidor de Tenerife, a su hija Inés Benitez de las Cuevas, por su matrimonio con Agustín de Herrera Saavedra, señor de Lanzarote y Fuerteventura, de ocho mil ducados de oro. Año 1553.

49. Promesa de arras y propter nupcias que Agustín de Herrera Saavedra, señor de Lanzarote y Fuerteventura, hace a su esposa Inés Benítez de las Cuevas, de mil ducados de oro, lo que hace una suma, entre dote y arras, de nueve mil ducados de oro, para cuya seguridad Agustín le hipoteca a ellos las partes que tiene o tuviere, en adelante, de las islas de Lanzarote y Fuerteventura, y todo lo que a ellas esté vinculado. Año 1553.

50. Carta de pago que hace Agustín de Herrera y Saavedra, señor de Lanzarote y Fuerteventura, a su suegro Pedro de Aponte, regidor de Tenerife, por dos cuentos y noventa y nueve maravedies que este pagó a cuenta de la dote prometida al primero por su matrimonio con Inés Benitez de las Cuevas. E1 pago se hizo en diversas partidas. Año 1554.

51. Finiquito que otorga Agustín de Herrera Saavedra, señor de Lanzarote y Fuerteventura, a su suegro, Pedro de Aponte, regidor de la isla de Tenerife, ausente, de un cuento y quinientos mil trescientos maravedíes de moneda

52 Archivo Histórico de la Nobleza, Fondo Frías, C. 963, D. 02

53 AGS, Cámara de Castilla, leg. 2.125. 
buena de Castilla, que es el resto de los ocho mil ducados de oro que le había prometido como dote por el matrimonio con su hija Inés Benitez de las Cuevas. Año 1555.

52. Reconocimiento de deuda que Agustín de Herrera Saavedra, señor de Lanzarote y Fuerteventura, hace a Pedro de Aponte, su suegro, regidor de Tenerife, ausente, de dos mil cincuenta doblas de oro, de quinientos maravedies cada una, de moneda corriente de estas islas, las cuales le prestó para comprar del Conde de Portoalegre y sus herederos loa cuatro doceavas partes que tienen de las islas de Lanzarote y Fuerteventura. Año 1555.

53. Finiquito que Agustín de Herrera Saavedra, señor de Lanzarote y Fuerteventura, da su suegro, Pedro de Aponte, regidor de Tenerife, ausente, por la dote que le prometió a causa del matrimonio contraído con su hija Inés Benítez de las Cuevas. Declara haber recibido un millón quinientos treinta mil maravedíes de moneda buena de Castilla en diversas cédulas. Además, declara haber recibido mil doscientos setenta y dos ducados que por él pago Pedro de Aponte a Bastián de Polanco, el cual los cobró por Juan de Maluenda y Gonzalo Pérez de Polanco, por otros tantos que de Agustín de Herrera recibió fray Antonio de las Cuevas en Lisboa, y en otros cuatrocientos setenta y tres ducados que por él pago Pedro de Aponte a Bartolomé Enríquez y Pedro Hernández, mercaderes, vecinos de Madeira, que él les debía por otros tantos que estos le habian prestado a fray Antonio de las Cuevas en Lisboa para comprar las cuatro doceavas partes que el duque de Avero tenía en Lanzarote y Fuerteventura. Año 1559.

54. Reconocimiento de deuda que Agustin de Herrera Saavedra, señor de Lanzarote y Fuerteventura, hace a Pedro de Aponte, su suegro, regidor de Tenerife, ausente, de ciento veintisiete ducados de oro, de a once reales cada uno, que son por razón del resto de los seiscientos ducados que Pedro de Aponte pagó en nombre de su yerno a Bartolomé Enríquez, mercader. Año 1559.

55. Venta que hace Juan de Guzmán, vecino de la ciudad de Sevilla, como tutor de Sancha de Herrera, hija de Francisco de Saavedra y Maria de Ábalos, a Agustín de Herrera, conde de Lanzarote, de las dos doceavas partes que Sancha posee en Lanzarote y Fuerteventura, con sus frutos, rentas y quintos, por un valor de nueve mil ducados. Año 1560.

56. Institución de mayorazgo hecha por el I marqués de Lanzarote, Agustín de Herrera y Rojas, en su hija Constanza de Herrera y Rojas.

Contiene licencia real, dada por Felipe II, para legitimar a las hijas del marqués, Juana de Herrera y Constanza de Herrera; nombramiento de Gaspar Peraza como tutor de Constanza, la toma de posesión por parte de este de todos los bienes vinculados en nombre de la mayorazga, y el acta del Cabildo de Lanzarote en la que se declara guardar y cumplir la escritura de mayorazgo. Año 1576.

57. Ratificación que hace Inés Benítez de las Cuevas, primera marquesa de Lanzarote, de la rectificación del mayorazgo hecha por su marido, el primer marqués de Lanzarote Agustín de Herrera y Rojas. Año 1586. 
Finalmente, en 1633, fallecido el tercer marqués de Lanzarote a la edad de siete años, su madre, Luisa Bravo de Guzmán, solicitó los derechos de sucesión del estado de Lanzarote y Fuerteventura como heredera de su hijo, pero litigan contra ella Antonio de Herrera y Rojas, hijo de Juana de Herrera (hija legitimada del I marqués) y dos miembros de la familia Sandoval, que reivindican ser los sucesores de la casa de Denia, llamada por el I marqués a la sucesión del mayorazgo en el que estaban incluidos los derechos señoriales ${ }^{54}$. Ante esta situación, las partes litigantes solicitaron conocer los documentos que se custodiaban en el archivo del marquesado, probablemente con la intención de saber cuáles eran las propiedades y derechos derivados del estado de Lanzarote. De manera que:

El governador $y$ oidores del Audençia del rey y nuestro señor, etc. A bos, el capitán Alonso de Xerés Cardona, alcalde mayor de la isla de Lanzarote, saved que en beinte $y$ tres de este mes de disienbre $y$ año de seisçientos y treinta y tres, se presentó ante nos el escrito del tenor siguiente: Cristóbal de Balderama Palomeque, en nonbre del marqués de Senete, duque del Infantado, dijo que por muerte del segundo marqués de Lanzarote y de la marquessa, su madre, quedaron mucha cantidad de papeles, asi en esta isla como en la de Lanzarote, pertenescientes a el estado dél, asi en baúles como sueltos y particularmente en dos baúles que la dicha marquessa, quando bino a esta isla este presente año dejó serados, el uno que tan solamente tiene los papeles tocantes a el dicho estado, y el otro de papeles tocantes a la dicha marquessa y algunos de inportancia. Los quales coren [sic] nuebo riesgo de perderse y ocultarse, y para que estén siguros conbiene se pongan en buen cobro y se depositen en persona de satisfaçión por inbentario, asistiendo a ello persona de confiança por presençia del escrivano. A buestra señoría pido y suplico mande se inbentarien todos los dichos papeles y que, si no paresieren las llaves de los baúles, se desclaven, y que por ante el escrivano público y la persona que buestra señoria nonbrase para ello se ponga en persona de sastifaçión en depósito para que no se entreguen a persona alguna sin mandato de buestra señoría, despachándome su probiçión y comiçión para todo y pido justicia. Y presentó poder de mi parte Cristóbal de Balderrama. Y por nos bisto, le mandamos dar y dimos la presente en la dicha racón [sic], por la qual los mandamos que beáis el dicho escrito que de suso ba inserto, y sabréis la parte y lugar donde están los dichos baúles de papeles, apremiando a la persona o personas que tubieren las llaves dellos a que las esivan ante bos. Y en casso que no parescan las llaves, haréis desclavar y abrir por buestra presençia con asistencia de Lucas Gutieres, quintador del estado, y por ante Juan de Gança, escrivano público de esa isla, y ante él mismo haréis inbentario de todos los dichos papeles con mucha lus y claridad. $Y$ hecho el dicho ynbentario, haréis forar y seraréis los dichos baúles quedando en poder del dicho escrivano, llevando bos la una llave y la otra el dicho Lucas Gutieres,

54 SEVILLA GONZÁLEZ, María del Carmen: "A propósito de los pleitos sucesorios...", art. cit. 
remitiendo testimonio del dicho inbentario a poder del presente escrivano de cámara. Y hasta que se bea, no deis testimonio a ninguna parte, a las quales para ello se sitó que para ello y las diligen çias que fueren nesesarias haser. En raçón de ello os dimos comiçión en forma, y lo cunpliréis asi los unos y los otros, pena de dies mill maravedis para la Cámara de su magestad y estrados de esta Audençia. So la qual pena mandamos a qualquier scrivano la notifique y dé testimonio. Dada en Canaria, a beinte y quatro de disienbre de mill y seiscientos y treinta y tres años. Juan de Ribera Sambrana, doctor, don Andrés Corionero de Figueroa, el doctor don Juan de Bohorques y Andrade. Yo, Francisco de la Crus, escrivano de cámara de la Real Audençia de estas islas y su acuerdo, lo fise escrivir por su mandado55.

A continuación se presentan los documentos recuperados a través de la documentación presentada a este último pleito de la primera línea sucesoria del marquesado de Lanzarote 56 :

58. Título de conde a Agustín de Herrera y Rojas por parte de Felipe II. Año 1567.

59. Carta ejecutoria dada a Agustín de Herrera y Rojas, ratificándole el uso del título concedido de conde de Lanzarote tras el pleito planteado ante la Cámara de Castilla por Pedro de Ribera, en nombre de Sancha de Ribera y Saavedra, su nieta, propietaria de dos doceavas partes de Lanzarote y Fuerteventura, y Gonzalo de Saavedra, propietario de una doceava parte. Año 1569.

60. Ratificación del mayorazgo que hizo don Agustín de Herrera y Rojas, conde de Lanzarote y señor de la isla de Fuerteventura, en doña Constanza Sarmiento, su hija, con licencia y real facultad del rey don Felipe II. Año 1580.

61. Título de marqués concedido por su majestad Felipe II a Agustín de Herrera y Rojas, conde de Lanzarote. Año 1584.

62. Donación de bienes que Agustín de Herrera y Rojas, primer marqués de Lanzarote, hizo a su nieto Agustín de Herrera y Rojas, hijo de Constanza de Herrera y Gonzalo Argote de Molina. Año 1586.

63. Testamento de la primera marquesa de Lanzarote, Inés Benítez de las Cuevas. Año 1588.

64. Testamento que otorgó Agustín de Herrera y Rojas, primer marqués de Lanzarote. Año 1598.

65. Tutela que Mariana Enríquez Manrique de la Vega, marquesa de Lanzarote, tenía de su hijo Agustín de Herrera y Rojas, segundo marqués de Lanzarote. Año 1598.

55 Archivo Histórico de la Nobleza, Fondo Osuna, C. 2.594, D. 3.

56 Todas las referencias que siguen han sido extraídas de Archivo Histórico de la Nobleza, Frías, C. 963. Agradezco a Aránzazu Lafuente, directora del Archivo Histórico de la Nobleza, el haberme aportado la referencia de este fondo. 
66. Arrendamiento de las tierras del mayorazgo que hizo Mariana Enríquez Manrique de la Vega, marquesa de Lanzarote, como tutora y curadora del segundo marqués de Lanzarote, su hijo, Agustín de Herrera y Rojas. Año 1598.

67. Auto de la Real Audiencia de Canarias concediendo a Mariana Henríquez Manrique de la Vega, marquesa de Lanzarote, lo necesario para la manutención de su hijo. Año 1599.

68. Información que hizo Mariana Manrique Enríquez de la Vega, marquesa de Lanzarote, como curadora de su hijo Agustín de Herrera y Rojas, segundo marqués de Lanzarote, sobre que Juana de Herrera y Rojas, de quien pretendió ser hijo Antonio de Herrera, no era hija legítima del primer marqués. Año 1609.

69. Probanza de la marquesa Mariana Enríquez Manrique de la Vega, en la causa que sigue contra Francisco de Acciayoli y Juana de Herrera, sobre la filiación de esta. Año 1609.

70. Real provisión de Felipe IV mediante la que comisiona al licenciado Francisco de Molina para que secuestre y administre el mayorazgo de Lanzarote, en lo que se resuelve el pleito que pende del Consejo de Castilla relativo a la sucesión del tercer marqués de Lanzarote. Año 1634.

71. Inventario del archivo del marquesado de Lanzarote contenido en dos baúles, realizado a petición del marqués de Zenete y duque del Infantado tras la muerte el segundo marqués y su madre, por los señores Alonso de Jerez Cardona, capitán y alcalde mayor de la isla de Lanzarote, Lucas Gutiérrez Melián, quintador, y el propio escribano autorizante. Anteceden las solicitudes y autorizaciones pertinentes para proceder al inventario de los documentos y nombramiento de los actuantes. Año 163457.

\section{Conclusiones}

Los inicios de la conquista normanda de Canarias no estuvieron exentos de quejas y reclamaciones, las cuales fueron más abundantes tras la concesión de mercedes a diversas personas lo que, junto a contradicciones en las licencias reales, alteración del orden por parte de los vasallos de las islas y cuestionamiento de las potestades de los señores que las poseían, fueron caldo de cultivo para disputas, pesquisas y pleitos en los que los señores, primero, y los marqueses, posteriormente, debieron testimoniar sus derechos. En este contexto, que se extendía a lo largo de siglos, el archivo del antiguo marquesado de Lanzarote fue un instrumento de legitimación del dominio y de los derechos señoriales, y el recurso a él fue frecuente.

Esta situación tomó especial relevancia con las islas bajo el gobierno de Inés Peraza, como heredera del archipiélago, y su marido Diego García de Herrera, y ya fue casi permanente.

Los expedientes derivados de pesquisas y juicios nos han servido como fuente esencial para la recuperación de documentos que por otras vías no podian localizarse. Un total de setenta y un documentos que cubren un periodo

57 Archivo Histórico de la Nobleza, Osuna, C, 2.495, D 3. 
cronológico que abarca del siglo XV al XVII, siendo más relevantes los anteriores a 1618, período histórico menos conocido y estudiado por la historiografía ante la escasez de fuentes en las islas como consecuencia de los ataques piráticos sufridos y la consecuente quema de los archivos, entre los que pudo estar el del propio marquesado en algún momento.

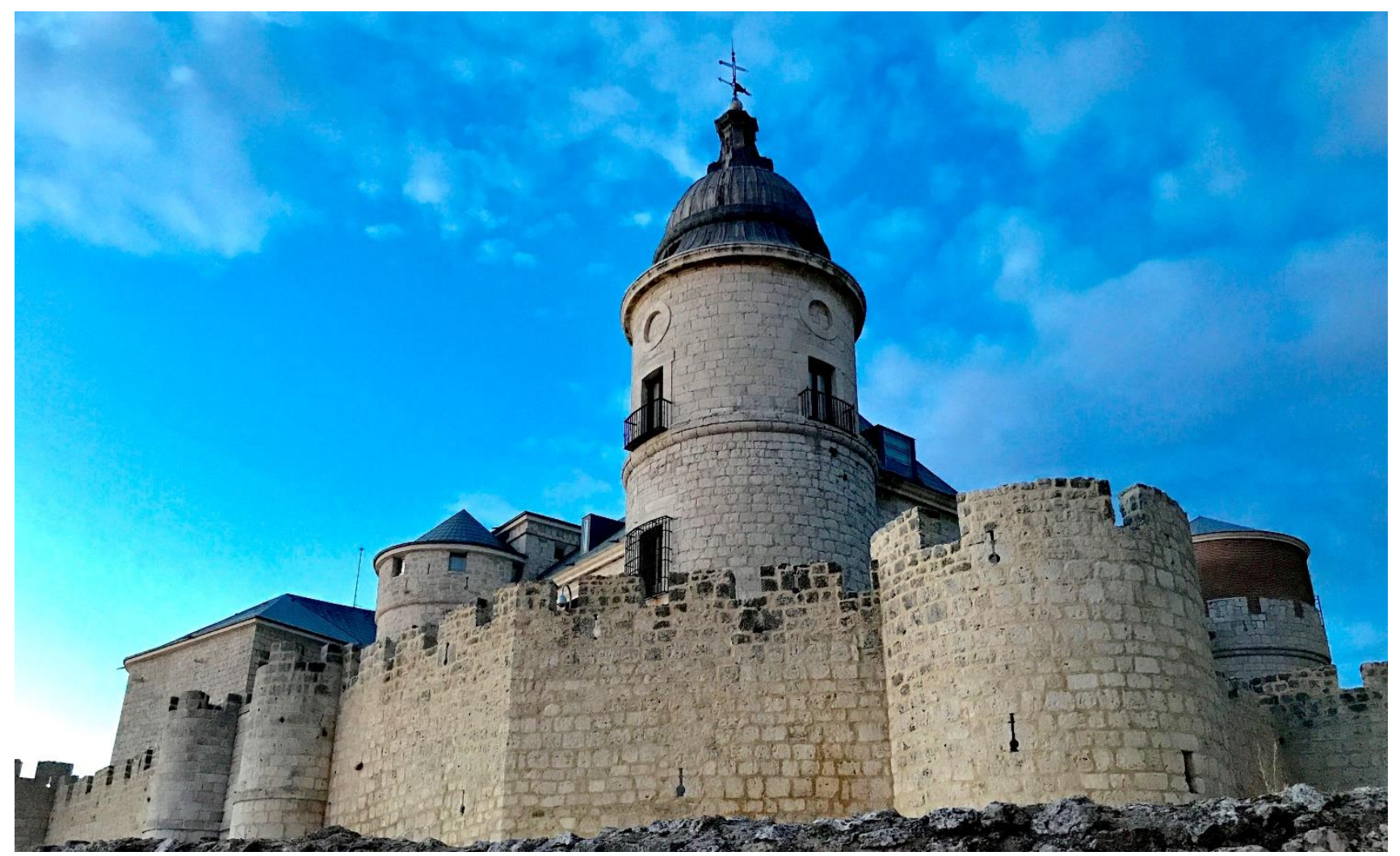

Imagen: Archivo General de Simancas, donde su custodian algunos de los procesos mencionados en el artículo (Foto del autor). 